\title{
Determination of Sulphur in Organic Products
}

T

HE methods in general use for the determination of sulphur in animal and vegetable products for sulphur-balance experiments with cattle and sheep depend upon the oxidation of not more than a gram of material with copper nitrate (S. R. Benedict, 1909) or fusion with sodium peroxide (R. E. Evans, 1931). From a material like hay with a small percentage of sulphur, the amount of barium sulphate finally obtained from $1 \mathrm{gm}$. does not exceed $2 \cdot 5 \mathrm{mgm}$., so that liability to error is considerable.

To overcome this disadvantage, F. J. Warth and T. S. Krishnan have devised a method in which much larger amounts of the substance can be treated, consisting in a nitric acid oxidation followed by alkali fusion, the latter step being essential for complete oxidation of the sulphur (Ind. J. Veterin. Sci. and Animal Husbandry, 5, Pt. 3, September 1935, p. 210). For urine, 100 c.c. may be treated with $10-15$ c.c. concentrated nitric acid and slowly heated on a sand bath until gentle effervescence commences. The beaker is then removed, and the reaction allowed to proceed in the cold until complete. After re-heating, and cooling overnight, nitrophenols and hippuric acid are filtered off, the filtrate is concentrated to a small volume, rediluted and again concentrated, this treatment being repeated until dilution causes no turbidity. The yellow solution is then made up to 100 c.c., and an aliquot taken for fusion, for which 5 c.c. of 50 per cent sodium hydroxide are added, mixed, and the whole is transferred to a silver basin. The water is evaporated off, and the dry residue is heated on the sand bath and finally fused. The fusion is completed in a few minutes, resulting in a pure white melt which is dissolved in water, treated with hydrochloric acid to remove nitric acid, filtered to remove small amounts of silver chloride and silica, and is then ready for precipitation of barium sulphate in the usual way.

For foodstuffs, such as hay and cake, and fæces, 5-10 gm. of substance is oxidised with boiling nitric acid for six hours. The contents of the flask are transferred to a beaker, diluted and allowed to stand overnight. The liquid is filtered, the filtrate concentrated in a beaker to a volume of 25 c.c., covered with a watch glass, and gently boiled and concentrated, which causes further oxidation with production of brown fumes. More acid is added, if necessary, until oxidation is complete. The liquid is then cooled, diluted and, if necessary, filtered. It is then evaporated on the water-bath, 10 c.c. of 50 per cent sodium hydroxide and 1-2 gm. of potassium nitrate are added, the whole is transferred to a silver dish, dried and fused.

For some materials, for example, grass, it may be desirable to deal with $100 \mathrm{gm}$. of material. For this, $100 \mathrm{gm}$. or thereabouts is weighed into a litre beaker, 500 c.c. of dilute ( $1: 3)$ nitric acid is added, and the whole is heated in order to start a gentle reaction. The source of heat is then removed, and the reaction is allowed to proceed to completion, with stirring. The beaker is then again heated, covered and the contents boiled vigorously for twelve hours, with addition of water to maintain the volume. The mixture is allowed to stand overnight, filtered on a Büchner funnel and thoroughly washed with nitric. acid-water. The filtrate and washings are finally made up to 2,000 c.c., and an aliquot of 100 c.c. used for the determination of sulphur by fusion.

\section{Pleistocene}

$\mathrm{V}$ ARIOUS lines of scientific investigation are now converging on the chronological problems of geology, prehistoric archæology and palæontology. The investigation of sedimentary deposits in Scandinavia by De Geer, and A. E. Douglass's tree-ring chronology in the south-western United States are instances in point. The application of the results of the study of solar radiation to the Pleistocene chronology of Central Europe has been reviewed by Dr. Friedrich E. Zeuner in relation to the evidence of geology, prehistoric archæology and palæontology (Geol. Mag., 72, 19, 350-376; 1935).

During the last twenty years, the Pleistocene of Central Europe has been investigated by a great number of geologists, with the result that a detailed stratigraphy has been established, which is generally applicable. When the 'radiation curve' of Milankovitch is applied to this stratigraphy, it becomes possible to date exactly fossils, skeletal remains and prehistoric implements from certain localities in thousands of years.

\section{Chronology}

On the evidence of the north German area of glaciation, the Alpine area of glaciation and the 'peri. glacial zone' (middle and south Germany), it is possible to formulate a correlation for which, as a matter of convenience, the Alpine terminology of Penck and Brückner may be used. This system of stratigraphy extends over a wide area. The Silesian Pleistocene links up the north-west and mid-German areas with Poland and Russia, while the Ukrainian loesses admit of a detailed subdivision with the same accuracy as the loess of Central Europe. In north Russia the same conditions prevail as in Germany, and the Caucasian mountains exhibit the same Pleistocene divisions. The later glacial phases (Riss and after) are thus represented in the whole of Central and Eastern Europe.

An outstanding point to emerge is that every glaciation of the old north German and Alpine divisions now appears to consist of two cold phases, which belong closely together. The Würm glaciation, however, includes a third and smaller phase. Two 
cooler phases of less intensity are intercalated between Mindel 2 and Riss 1 and between Riss 2 and Würm 1. These have not yet been found outside central and south Germany. There are several cold phases older than Günz, but up to now they have only been proved for the Alps and a few river systems. They are older than the 'Diluvium', and possibly are contemporary with the earliest Pleistocene and Upper Pliocene of England.

In Milankovitch's radiation curve (all calculations are as from A.D. 1800) there are strong minima of solar radiation in a group of three at $23,000,72,000$ and 115,000 years; of two at 188,000 and 230,000 years; a long period without stronger minima of radiation stands between 240,000 and 430,000 years; there is another group of two minima at $\mathbf{4 3 5 , 0 0 0}$ and 476,000 years ; and an early group of two minima at 550,000 and 591,000 years. It can scarcely be coincidence that this arrangement is exactly the same as was found for the glacial phases of the Pleistocene. Not only are the threefold Würm and the doubled Riss, Mindel and Günz represented by strong minima of radiation, but also the great interglacial Mindel 2Riss 1 finds its equivalent in a period of nearly 200,000 years. The coincidence of so many details is almost amazing. An application of the curve solves many of the old problems of stratigraphy, as well as raises new.

The absolute chronology thus afforded also dates the remains of fossil man and his cultures more accurately than hitherto, but only provided their exact position in the stratigraphical succession has been determined. The most ancient find in Central Europe, Homo heidelbergensis from the Mauer sands, cannot be later than the interglacial between Günz 2 and Mindel 1. Many have correlated him with the Chellean, but it is not impossible to assign him a pre-Chellean culture with a place in the absolute scale of about 500,000 years. The Acheulean at Achenheim occurs in the loess of Riss 2 and falls within a glacial phase, though the evidence from Markleeberg suggests that it may extend further back, giving a possible antiquity of 183,000 years. The Mousterian stations Taubach and Ehringsdorf show that Neanderthal man was present in Germany in the last phase of the Interglacial Riss/Würm, and was still living there when the climate became colder with the advance of the Würm glaciation; while Wallertheim shows that he was there after the maximum of Würm 1. This dating indicates an antiquity covering the period from 140,000 to 105,000 . The Aurignacian, on the evidence from Linsenberg near Mayence, belongs to the beginning of Würm 2 and is dated from 95,000 to 69,000 and is followed by the Solutrean of Predmost, of which the precise age has still to be determined; but it is suggested on the strength of evidence from Kesslerloch that the Solutrean stands at 67,000. The Kesslerloch Magdalenian site was inhabited some time after the maximum of Würm 2, and most German Magdalenian is of about the same period; while in north Germany (Balver Höhle, Westphalia) the end of the Mag. dalenian is Würm 3. The whole Magdalenian is dated at 65,000 to 18,000 ; while the Mesolithic, after Würm 3, is assigned to 15,000 to 7,500 and the Neolithic in the post-glacial Atlantic phase dated 7,500 to 4,000 . (All dates are reckoned in years before A.D. 1800.)

In palæontology, the new chronology makes it possible to date the disappearance of ancient species and the appearance of new ones very exactly. We are enabled to study migrations and other alterations in the distribution of species with precision. For example, the hippopotamus, absent in Central Europe, except in the Rhine Valley, where it is typical of the early Pleistocene, persists into late Middle or even Upper Pleistocene in England. It can thus be shown to have survived in western Germany for a 100,000 years after it had disappeared from the rest of mid-Europe, while it survived in the oceanic climate of England for another 200,000 years longer.

The new chronology also enables us to estimate the time necessary for adaptation and other alterations of specific characters, of which the most intelligible instance is afforded by the elephants. Thus $E$. antiquus, a forest species, in 450,000 years developed very little; but in the same period $E$. primigenius shows a very marked specialisation owing to a new biotope. The Siberian mammoths may be about 15,000 years old. For the whole evolution of the mammoth the absolute chronology

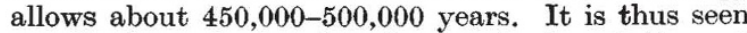
to afford a criterion for the speed of evolution, of which we know very little.

\section{Coal and Gas in Great Britain}

\begin{abstract}
A $\mathrm{T}$ the seventy-third annual meeting of the A Institution of Gas Engineers in London on May 26-29, the address of the president, Colonel W. Moncrieff Carr, referred to "perhaps the most serious problem in the history of the Industry" - the proposed coal selling scheme, under which not only the prices but also the choice of gas coal would be apparently at the discretion of the coal industry, which would thus acquire uncontrolled monopolistic power. It is feared that the coal industry's policy will be influenced by a desire voiced by its spokesmen and indicated by its commercial actions to discourage the replacement of raw coal by the products of coal carbonisation, even though this conduces to public amenity and hygiene and to private convenience.
\end{abstract}

Moreover, freedom of choice of raw material is vital to any manufacturing industry and especially where the raw material can be so variable as coal.

At the moment, the public gas supply is being concentrated into fewer and larger units by several paths-amalgamations of adjacent undertakings, by the establishment of 'gas grids' where local circumstances are favourable, and by the formation of holding companies controlling many but not neces. sarily adjoining undertakings. The merits and demerits of these activities are engaging much attention, to which a paper by Mr. F. C. Briggs on the Dudley Gas Amalgamation contributed. In south Yorkshire the coking industry produces an abundant supply of gas as a by-product which the 